\title{
IKK $\beta$ Activation in the Fetal Lung Mesenchyme Alters Lung Vascular Development but Not Airway Morphogenesis
}

\author{
Alyssa M. McCoy, ${ }^{* \dagger}$ Jennifer L. Herington, ${ }^{\S}$ Ashley N. Stouch, ${ }^{* \dagger \S}$ Anamika B. Mukherjee, ${ }^{\S}$ Omar Lakhdari, ${ }^{* \dagger}$ \\ Timothy S. Blackwell, ${ }^{\S}$ and Lawrence S. Prince ${ }^{* \dagger}$

\begin{abstract}
From the Department of Pediatrics, * University of California, San Diego, La Jolla, California; the Rady Children's Hospital, ${ }^{\dagger}$ San Diego, San Diego, California; the Department of Neuroscience and Pharmacology, ${ }^{\ddagger}$ Meharry Medical College, Nashville, Tennessee; and the Departments of Pediatrics, Medicine, Cancer Biology, and Cell and Developmental Biology, ${ }^{\S}$ Vanderbilt University, Nashville, Tennessee
\end{abstract}

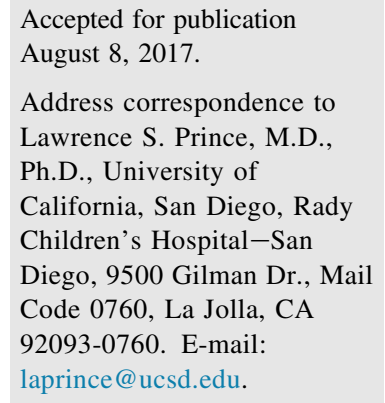

\begin{abstract}
In the immature lung, inflammation and injury disrupt the epithelial-mesenchymal interactions required for normal development. Innate immune signaling and NF- $\kappa$ B activation disrupt the normal expression of multiple mesenchymal genes that play a key role in airway branching and alveolar formation. To test the role of the NF- $\kappa B$ pathway specifically in lung mesenchyme, we utilized the mesenchymal Twist2-Cre to drive expression of a constitutively active inhibitor of NF- $\kappa B$ kinase subunit $\beta$ (IKK $\beta c a$ ) mutant in developing mice. Embryonic Twist2-IKK $\beta$ ca mice were generated in expected numbers and appeared grossly normal. Airway branching also appeared normal in Twist2-IKK $\beta$ ca embryos, with airway morphometry, elastin staining, and saccular branching similar to those in control littermates. While Twist2-IKK $\beta$ ca lungs did not contain increased levels of $I l 1 b$, we did measure an increased expression of the chemokine-encoding gene $C$ Cl2. Twist2-IKK $\beta$ ca lungs had increased staining for the vascular marker platelet endothelial cell adhesion molecule 1 . In addition, type I alveolar epithelial differentiation appeared to be diminished in Twist2-IKK $\beta$ ca lungs. The normal airway branching and lack of Il1b expression may have been due to the inability of the Twist2-IKK $\beta$ ca transgene to induce inflammasome activity. While Twist2-IKK $\beta c a$ lungs had an increased number of macrophages, inflammasome expression remained restricted to macrophages without evidence of spontaneous inflammasome activity. These results emphasize the importance of cellular niche in considering how inflammatory signaling influences fetal lung development. (Am J Pathol 2017, 187: 2635-2644; https://doi.org/10.1016/j.ajpath.2017.08.013)
\end{abstract}

In preterm infants, inflammation and injury inhibit normal lung development and lead to the chronic lung disease bronchopulmonary dysplasia. $^{1-5}$ Sources of inflammation include elevated inspired oxygen concentrations, mechanical stretch due to positive-pressure ventilation, and both prenatal and postnatal exposure to microbes. In animal models, inflammation in the developing lung arising from these various sources disrupts the normal epithelial-mesenchymal interactions required for airway and alveolar morphogenesis. ${ }^{6-9}$ However, the cellular and molecular mechanisms connecting inflammation to abnormal development are still being characterized.
In response to microbial products or environmental exposures, lung macrophages mount an initial innate immune response. ${ }^{10,11}$ At the molecular level, the macrophage response is characterized by the activation and nuclear translocation of the transcription factor NF- $\kappa \mathrm{B} .{ }^{12-14}$ After NF- $\kappa \mathrm{B}$ activation, lung macrophages express and release a number of soluble inflammatory mediators that target adjacent cells within the lung tissue. ${ }^{15,16}$ Based on experiments using NF- $\kappa \mathrm{B}$ reporter

Supported by NIH grants HL086324 (L.S.P.), HL126703 (L.S.P.), HL097195 (L.S.P. and T.S.B.), and 5R25GM059994 (A.M.M.).

Disclosures: None declared. 
mice, the initial wave of NF- $\kappa \mathrm{B}$ activity in macrophages is followed by a later phase of NF- $\kappa B$ activation in surrounding mesenchymal cells. ${ }^{17}$ Spreading inflammation throughout the developing lung inhibits saccular airway branching morphogenesis in late-stage embryonic mouse lungs and alveolar formation in postnatal mouse lungs. ${ }^{17,18}$ While multiple inflammatory mediators can affect lung development, inflammasome activation and IL-1 $\beta$ release are required for inflammatory stimuli (both microbial products and environmental injury/hyperoxia) to disrupt airway branching and alveolar formation. ${ }^{18-20}$ Lung inflammation inhibits the expression of several key mesenchymal genes important for lung development, including FgflO and Itga8. ${ }^{21,22}$ In the case

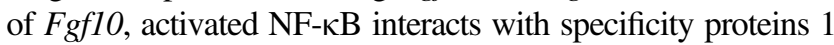
and 3 to reduce gene transcription. ${ }^{23,24}$

While macrophages play an important role in the initial inflammatory response, we wanted to test whether NF- $\kappa \mathrm{B}$ activation in mesenchymal cells could affect lung morphogenesis in a cell-autonomous manner. To bypass macrophages, we crossed mice expressing the mesenchymalspecific Twist2-Cre transgene with a strain expressing a constitutively active inhibitor of NF- $\kappa \mathrm{B}$ kinase subunit $\beta$ (IKK $\beta \mathrm{ca}$ ) mutant downstream of a loxP-flanked STOP cassette. Twist2-Cre animals display Cre activity throughout the lung mesenchyme during development, but spare the developing lung vasculature. ${ }^{25,26}$ The resulting doubletransgenic mice (Twist2-IKK $\beta$ ca) have increased IKK $\beta$ activity and subsequent NF- $\kappa \mathrm{B}$ activation in mesenchymal cell populations. Here we report that Twist2-IKK $\beta$ ca mice were viable with normal fetal airway development. Mesenchymal expression of IKK $\beta \mathrm{ca}$ was sufficient for stimulating the expression of the inflammatory chemokine-encoding gene $\mathrm{Ccl} 2$ and for recruiting macrophages to the fetal lung. However, Twist2-IKK $\beta$ ca lungs did not express elevated $I l l b$ levels or inflammasome complexes outside of the macrophage population. These results emphasize the unique impact of NF- $\kappa \mathrm{B}$ activation in different cell populations on tissue inflammation and lung development.

\section{Materials and Methods}

\section{Reagents}

The following reagents were used for immunofluorescence: rat anti-CD68 (Acris Antibodies, San Diego, CA), rat antiplatelet endothelial cell adhesion molecule 1 (CD31; BD Pharmingen, San Jose, CA), mouse anti- $\alpha$ smooth muscle actin-Cy3 (Sigma-Aldrich, St. Louis, MO), rat anti-Ecadherin (Thermo Fisher Scientific, Waltham, MA), rabbit anti-phospho histone H3 (EMD Millipore, Billerica, MA), hamster anti-podoplanin (T-1 $\alpha$; Developmental Studies Hybridoma Bank, University of Iowa, Iowa City, IA), rabbit anti-surfactant protein C (Abcam, Cambridge, MA), rabbit anti-green fluorescent protein (Invitrogen, Waltham, MA), rabbit anti-cryopyrin [(nucleotide-binding oligomerization domain-containing protein)-like receptor protein (NLRP)-3;
Santa Cruz Biotechnology, Dallas, TX], and rabbit anticaspase 1 p10 (Santa Cruz Biotechnology). Prolong Gold mounting media and fluorescent secondary antibodies Alexa Fluor 488 and 555 were purchased from Invitrogen. The nuclear stain DRAQ5 was purchased from Thermo Fisher. Cells and explants were cultured and treated in the following reagents: gel-purified Escherichia coli lipopolysaccharide (LPS) (O55:B5; Sigma-Aldrich), ATP (SigmaAldrich), Dulbecco's modified Eagle's medium (Corning Life Sciences, Tewksbury, MA), fetal bovine serum (Thermo Fisher), and penicillin-streptomycin (Thermo Fisher).

\section{Mice}

All experiments were approved by the Institutional Animal Care and Use Committee at Vanderbilt University and the University of California-San Diego. Twist2-Cre, Rosa ${ }^{\mathrm{mT} / \mathrm{mG}}$ and $\mathrm{B} 6(\mathrm{Cg})-G t(R O S A) 26 \operatorname{Sor}^{t m 4(I k b k b) R s k y} / \mathrm{J}$ mice were purchased from The Jackson Laboratory (Bar Harbor, ME). Twist2-IKK $\beta$ ca mutant mice were derived from Twist2$\mathrm{Cre}^{+27}$ X B6(Cg)-Gt(ROSA)26Sor ${ }^{t m 4(I k b k b) R s k y} / \mathrm{J}$ matings. ${ }^{28}$ Genotyping was performed by standard PCR. For timed matings, embryonic day zero (E0) was identified as the morning of vaginal plug confirmation.

\section{Cell and Explant Culture}

Fetal lungs were dissected and enzymatically digested with collagenase $(0.7 \mathrm{mg} / \mathrm{mL})$. Cells were passed through a 70 $\mu \mathrm{m}$ strainer and centrifuged. Cells were then plated in complete media. After macrophages were allowed to briefly attach, nonadherent cells (including mesenchymal cells) were collected and replated overnight. After passaging, cultures were $95 \%$ positive for $\alpha$ smooth muscle actin-expressing mesenchymal cells. Fetal lung explants were isolated and cultured as previously described. ${ }^{17}$ Brightfield images were captured at 24 and 72 hours of culture. Branch count analysis was performed using ImageJ software version $1.51(\mathrm{NIH}$, Bethesda, MD; http://imagej.nih.gov.ij).

\section{RNA Isolation and Real-Time PCR}

Total RNA was isolated from whole-lung macrophages and mesenchymal cells using TRIzol (Invitrogen). First-strand cDNA was synthesized using oligo(dT) primers and Superscript III (Invitrogen). Real-time PCR was performed using either SYBR Green or TaqMan probes. PCR was performed using a CFX96 thermocycler (Bio-Rad Laboratories, Hercules, CA). The $2^{-\Delta \Delta C t}$ method was used for comparing gene expression in samples. All samples were normalized to glyceraldehyde-3-phosphate dehydrogenase. Experiments were performed at least three independent times. Data between groups were compared by analysis of variance or $t$-test for the identification of significant differences. 


\section{Immunoassay}

Isolated lung mesenchymal cells were cultured until $90 \%$ confluent. Cells were then treated with LPS $(250 \mathrm{ng} / \mathrm{mL})$, ATP $(5 \mathrm{mmol} / \mathrm{L})$, or both LPS + ATP. After treatment culture media were collected, levels of IL-1 $\beta$ were measured using enzyme-linked immunosorbent assay (BD Biosciences, San Jose, CA). Assays were performed in triplicate and in at least three independent experiments.

\section{Tissue Processing and Immunostaining}

Paraffin-embedded fetal mouse lungs were dissected and fixed in 4\% paraformaldehyde (Electron Microscopy Sciences, Hatfield, PA). Paraffin sections were then stained with hematoxylin (Dako North America, Carpinteria, CA), eosin (Ricca Chemical, Arlington, TX), and Hart's modified stain (reagents from Electron Microscopy Sciences). Hematoxylin and eosin-stained sections were measured for lung tissue and airspace volume using ImageJ. Frozen embedded fetal mouse lungs were fixed in $4 \%$ paraformaldehyde, washed, and processed through a sucrose gradient before being embedded in OCT media (Tissue-Tek; Sakura Finetek USA, Radnor, PA). Frozen sections were stained with antibodies of interest followed by Alexaconjugated secondary antibodies, and nuclei were stained with DRAQ5.

\section{Imaging and Image Analysis}

Confocal images were acquired using a TCS SPE laserscanning confocal microscope (Leica Microsystems, Buffalo Grove, IL). Widefield fluorescent and bright-field images of whole fetal mouse lung were obtained using an Olympus IX81 inverted microscope (Olympus, Center Valley, PA) with an Orca ER CCD camera (Hamamatsu Photonics, Bridgewater, NJ). All images were saved and imported to Photoshop software version CS6 (Adobe Systems, San Jose, CA) for processing. Identical processing parameters were used for achieving proper image comparison.

\section{Flow Cytometry}

The following antibodies were used for flow cytometry: CD45-V500, stem cells antigen-1-fluorescein isothiocyanate (BD Biosciences); CD140b-R-phycoerythrin, CD21phycoerythrin-cyanin 7, allophycocyanin-cyanin 7 (eBioscience); and E-cadherin-allophycocyanin (R\&D Systems, Minneapolis, MN). Viable cells were selected using Live/Dead fixable dead cell stain (Thermo Fisher). Fetal lungs were enzymatically digested into a single-cell suspension using collagenase type 2 (Worthington Biochemical Corporation, Lakewood, NJ). Red blood cells were lysed using ammonium-chloride-potassium lysing buffer (Invitrogen). Cells were placed on ice for 15 minutes in flow cytometry staining buffer (eBioscience) and incubated with antibodies for 30 to 60 minutes. For intracellular antibodies, cells were incubated on ice for 30 to 60 minutes using the Intracellular Fixation and Permeabilization Kit (eBioscience). Flow Cytometry measurements were
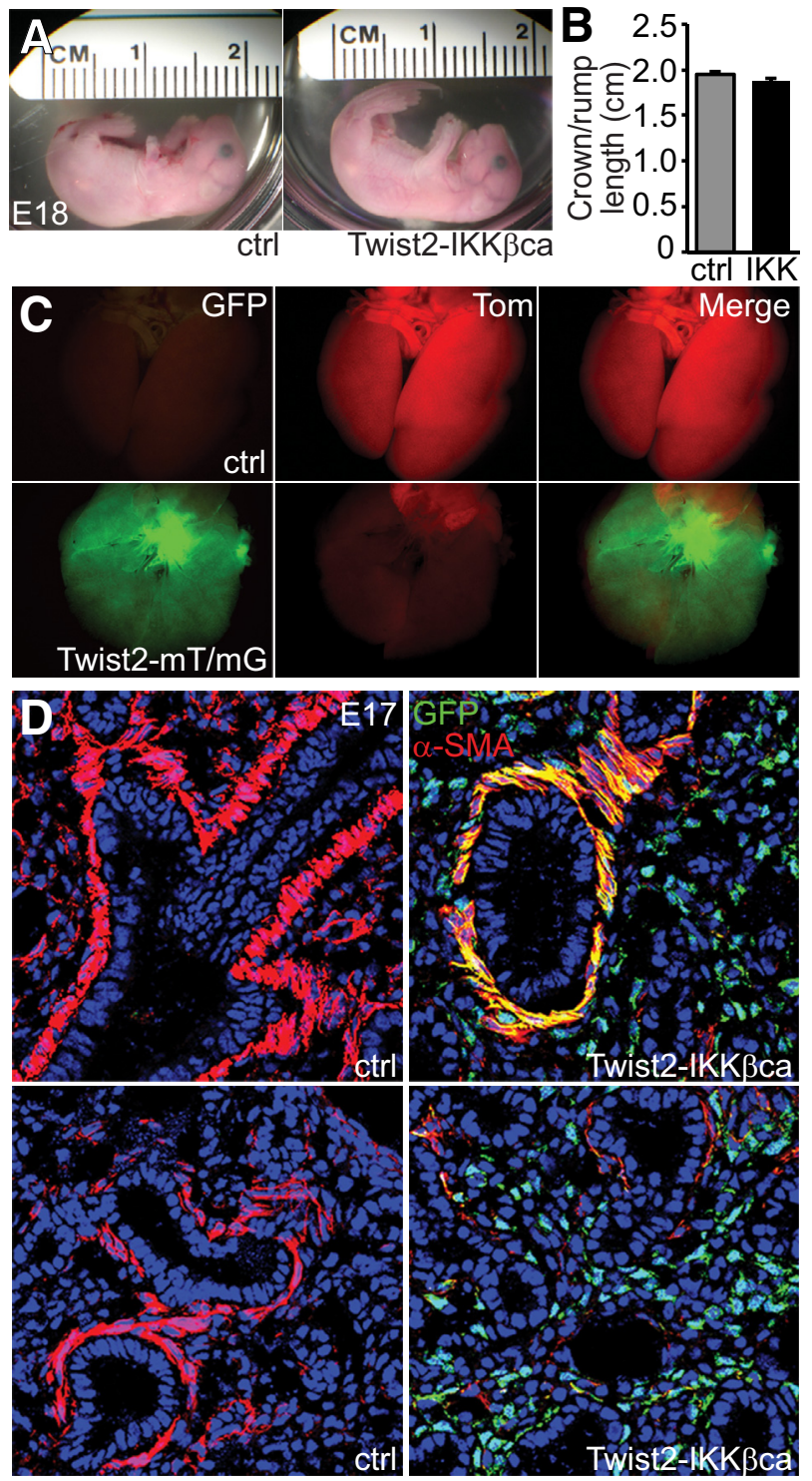

Figure 1 Twist2-driven expression of constitutively active inhibitor of NF-KB kinase subunit $\beta$ (IKK $\beta c a$ ) in fetal lung mesenchyme. Twist2-Cre $X$ $\mathrm{B} 6(\mathrm{Cg})-G t(R O S A) 26 S_{0} r^{\text {tm } 4(I k b k b) R s k y} / \mathrm{J}$ matings resulted in the expected genetic distribution of E15 and E18 embryos. E15: 44.7\% Twist2-IKKßca and 55.3\% Twist2-Cre ${ }^{-}$(94 embryos from 13 litters). E18: 55.7\% Twist2-IKKßca and 44.3\% Twist2-Cre ${ }^{-}$(70 embryos from 8 litters). Genotyping therefore suggested fetal and embryonic viability. A and B: E18 Twist2-IKK $\beta$ ca fetal pups (IKK) appeared to develop normal with similar crown to rump lengths compared with littermate controls (ctrl). C: Twist2-Cre mice were crossed with Rosa26 $6^{\mathrm{mT} / \mathrm{mG}}$ reporter mice, demonstrating Tomato fluorescence before Cre recombination and green fluorescent protein (GFP) expression throughout lung mesenchyme in embryos expressing Twist2-Cre. D: Twist2-IKK $\beta$ ca mice express internal ribosome entry site-mediated GFP in Twist2-Cre ${ }^{+}$mesenchymal cells. Laser scanning confocal immunostaining of E17 fetal lung sections showed GFPpositive mesenchymal cells and smooth muscle cells expressing $\alpha$-smooth muscle actin (SMA) surrounding airways. Nuclei stained with DRA05 (blue). Data are expressed as means \pm SD. $n=4$ control mice (B). Original magnification: $\times 4($ C $) ; \times 40$ (D). Tom, tomato fluorescence. 

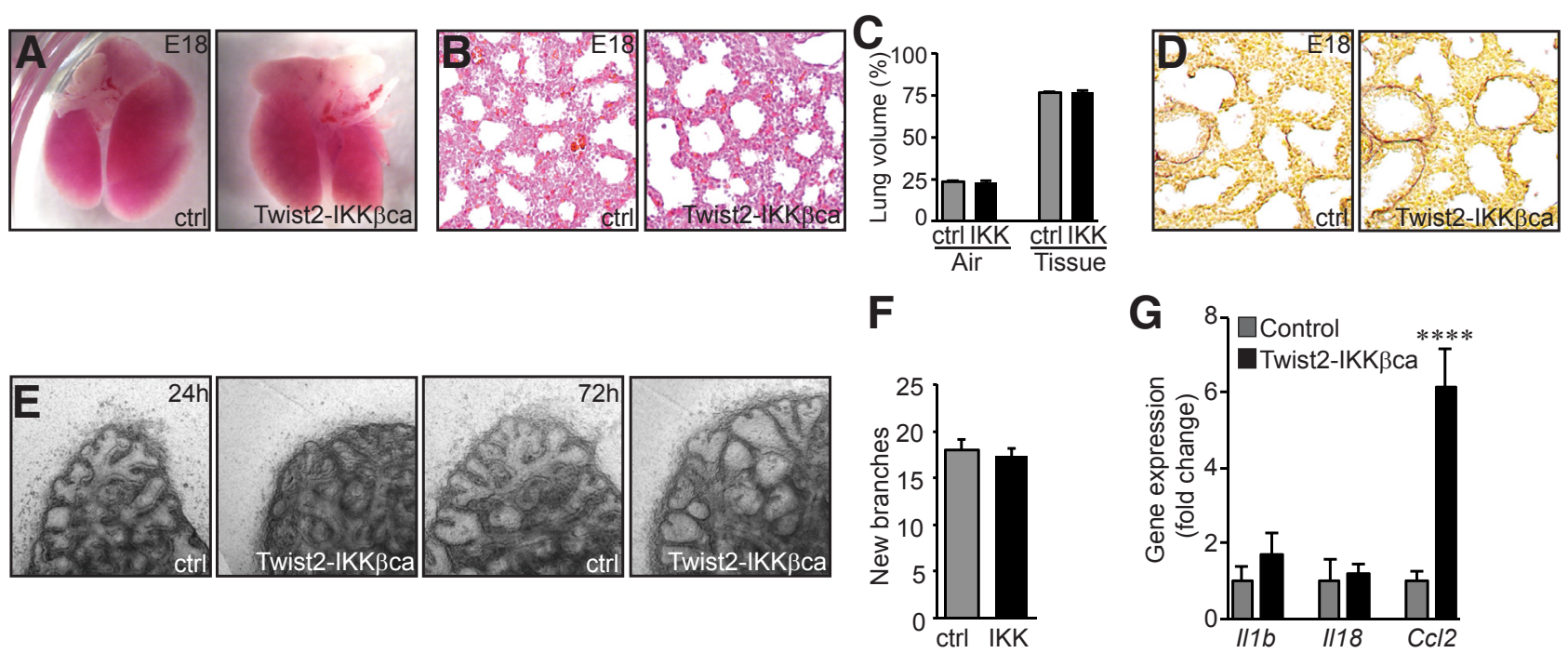

Figure 2 Constitutively active inhibitor of NF-KB kinase subunit $\beta$ (IKK $\beta c a$ ) expression in fetal mesenchyme does not disrupt lung airway morphogenesis. A: Similar overall size of E18 Twist2-IKK $\beta$ ca lungs compared with littermate controls. B: Hematoxylin and eosin stained sections of E18 lungs show similar airway and interstitial morphology in Twist2-IKK $\beta c a$ and littermate controls. C: Morphometry measurements showed no change in Twist2-IKK $\beta$ ca lungs compared with control littermates. D: Lung sections were stained with modified Hart's stain to visualize elastic fibers, which appear similar in Twist2-IKK $\beta c a$ and controls. E and F: E15 fetal mouse lung explants were cultured for 72 hours, with images acquired at 24 and 72 hours. Bright-field images show formation of new saccular airway branches along the periphery. While Twist2-IKK $\beta$ ca airways appeared slightly more dilated, airway branching was similar to controls (F). G: Expression of pro-inflammatory cytokines and chemokines were measured by real-time PCR using RNA isolated from E17 Twist2-IKK $\beta$ ca and littermate control fetal whole lungs. Twist2-IKK $\beta c a$ lungs had elevated mRNA levels of the chemokine $C c l 2$. Expression levels of Il1b and Il18 were similar to those in control littermates. Data are expressed as means \pm SD. $n=9$ to 15 mice $(\mathbf{C}, \mathbf{F}$, and $\mathbf{G})$. ${ }^{* * *} P<0.0001$ versus control. Original magnification: $\times 20$ (B and $\left.\mathbf{D}\right) ; \times 4$ (E).

conducted on a BD LSR II flow cytometer (BD Biosciences). For gating, doublets were excluded based on forward light scatter area against forward light scatter height followed by side light scatter area against side light scatter height. Data analysis was performed using FlowJo software version 9 (FlowJo, Ashland, OR).

\section{Results}

To test whether increased NF- $\kappa \mathrm{B}$ activation specifically in developing mesenchymal cells could affect lung development, we crossed Twist2-Cre transgenic mice ${ }^{27}$ with

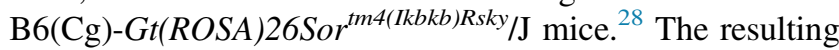
double-transgenic animals were predicted to express both a Ikbkbca mutant allele and enhanced green fluorescent protein in Twist $2^{+}$mesenchymal cell populations. Genotyping at embryonal days 15 and 18 detected approximately the predicted numbers of double-transgenic Twist2-Cre:B6(Cg)Gt(ROSA)26Sor ${ }^{t m 4(I k b k b) R s k y} / \mathrm{J}$ (Twist2-IKKßca) embryos, suggesting developmental viability (E15: 44.7\% Twist2IKK $\beta \mathrm{ca}$ and $55.3 \%$ Twist2-Cre ${ }^{-}, 94$ embryos from 13 litters; E18: 55.7\% Twist2-IKK $\beta \mathrm{ca}$ and $44.3 \%$ Twist2-Cre ${ }^{-}, 70$ embryos from 8 litters). Crown-rump measurements and gross appearance of Twist2-IKK $\beta \mathrm{ca}$ embryos were similar to those of control littermates (Figure 1, A and B).

To confirm Cre-mediated transgene expression in the fetal lung mesenchyme during embryogenesis, we crossed Twist2-Cre animals with the $\operatorname{Rosa}_{2} 6^{m T / m G}$ reporter strain. ${ }^{29}$ In dissected hearts and lungs from control (Twist2-Cre ${ }^{-}$) embryos, Tomato expression was observed throughout the lung and surrounding structures (Figure 1C). Twist2-Cre ${ }^{+}$ lungs expressed green fluorescent protein throughout the lung mesenchyme. In E17 Twist2-IKK $\beta$ ca embryos, we detected green fluorescent protein expression from the internal ribosomal entry site sequence downstream of the Ikbkbca allele throughout the lung mesenchyme. E17 Twist2-IKK $\beta$ ca lungs also expressed green fluorescent protein in $\alpha$ smooth muscle actin-positive smooth muscle cells along airways (Figure 1D). We next examined whether mesenchymal expression of the IKK $\beta$ ca affected overall lung and airway morphogenesis. Gross examination of mutant Twist2-IKK $\beta$ ca and control littermate lungs appeared similar at E18 (Figure 2A). Hematoxylin and eosin-stained sections showed a similar overall appearance of both the proximal and distal airways, with comparable airspace and tissue volume as measured by morphometry (Figure 2, B and C). Elastin staining overall was also similar between Twist2-IKK $\beta \mathrm{ca}$ and control lungs (Figure 2D).

We previously demonstrated that NF- $\kappa \mathrm{B}$ activation in macrophages could disrupt distal airway branching both in vivo and in cultured saccular stage explants. ${ }^{17}$ To test whether similar effects could be observed with mesenchymal NF- $\kappa$ B activation, we cultured E15 Twist2-IKK $\beta$ ca and littermate control explants, obtaining photomicrographs every 24 hours (Figure 2, E and F). While the airways in Twist2-IKK $\beta$ ca explants appeared slightly more dilated, the number of new distal airway branches formed between 24 and 72 hours of culture was similar to that in controls. These 

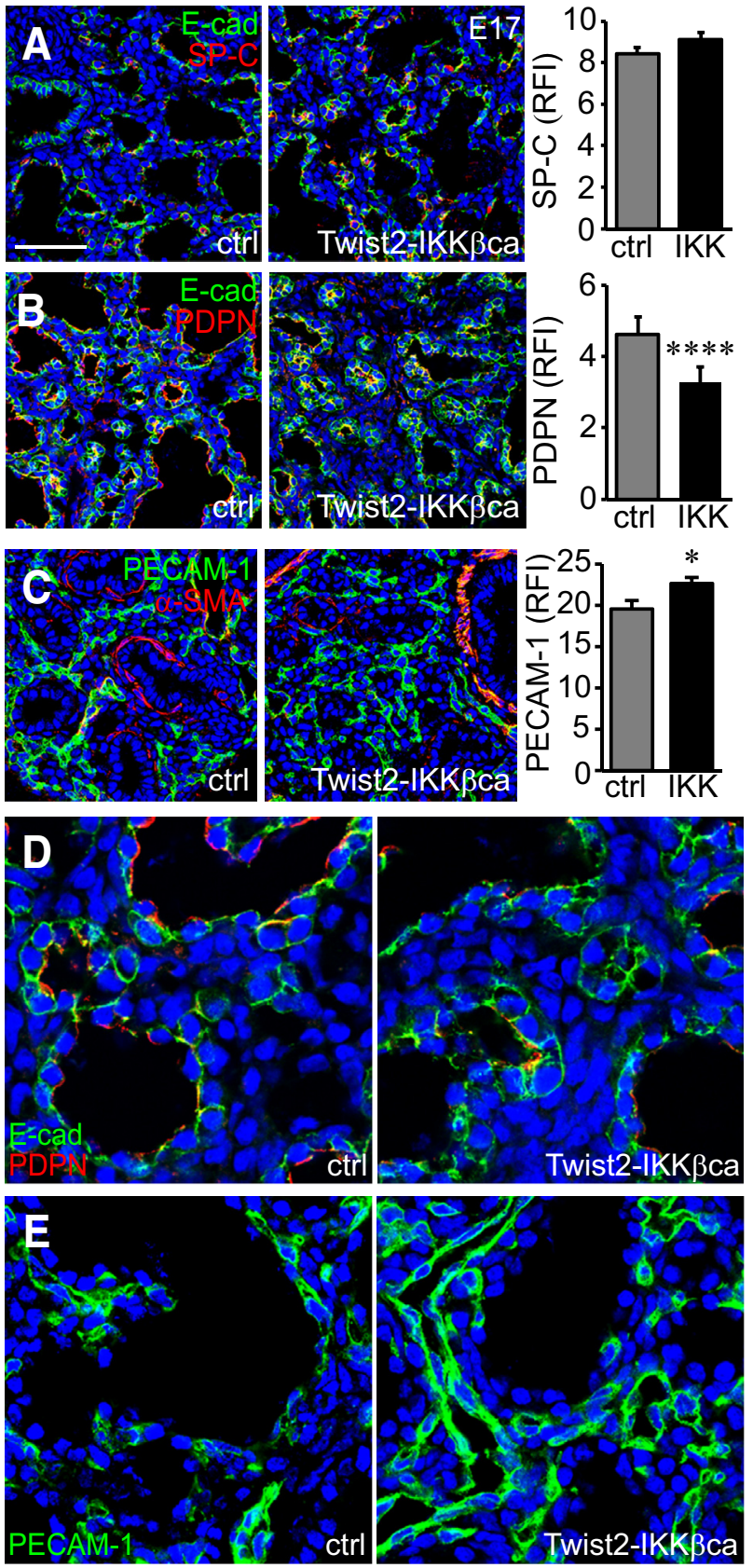

Figure 3 Alterations of Type I epithelial cell and vascular development in Twist2-constitutively active inhibitor of NF- $\mathrm{KB}$ kinase subunit $\beta$ (IKK $\beta \mathrm{ca}$ ) fetal lungs. E17 lungs from Twist2-IKK $\beta \mathrm{ca}$ and littermate control embryos were sectioned, immunostained, and visualized by laser scanning confocal microscopy. Relative fluorescence intensity (RFI) was quantified for each fluorescence channel across each image. A and B: Twist2-IKKßca embryos had similar expression of the Type II cell marker surfactant protein C (SP-C) (A), but reduced staining and RFI for the Type I cell marker podoplanin (PDPN) (B). Epithelial cells detected by E-cadherin (E-cad) immunolabeling. C: Twist2-IKK $\beta$ ca lungs had increased staining of the endothelial marker platelet endothelial cell adhesion molecule (PECAM)-1. Smooth muscle and mesenchymal cells detected by $\alpha$-smooth muscle actin (SMA) immunolabeling. D and E: Higher-magnification images show more detail regarding reduced PDPN staining (D) and increased PECAM-1 staining (E) in Twist2-IKK $\beta$ ca lungs. Nuclei labeled with DRAQ5 (blue). Data are expressed as means \pm SD. $n=30$ images. ${ }^{*} P<0.05,{ }^{* * *} P<0.0001$ versus control. Scale bar $=50 \mu \mathrm{m}(\mathbf{A}-\mathbf{C})$. Original magnification, $\times 63$ (D and $\mathbf{E})$. results, along with the lung morphometry measurements from lung sections, demonstrated that the mesenchymal expression of a IKK $\beta$ ca mutant was not sufficient for the disruption of fetal airway branching.

We initially hypothesized that Twist2-IKK $\beta$ ca embryos would have abnormal airway branching. To confirm that the IKK $\beta \mathrm{ca}$ isoform was sufficient for inducing the expression of NF- $\kappa \mathrm{B}-$ dependent inflammatory mediators, we used real-time PCR to measure the expression of several inflammatory genes in E17 whole-lung isolates. Twist2-IKKßca lungs had increased $C c l 2$, but similar $I l l b$ and $I l l 8$ expression, compared with control littermates (Figure 2G). Data from previous reports have implicated IL-1 $\beta$ in linking inflammation to altered airway morphogenesis. ${ }^{18-20}$ Therefore, the inability of the IKK $\beta$ ca mutant to increase $I l l b$ expression could explain the normal airway morphogenesis in Twist2-IKKßca embryos.

While increased IKK $\beta$ activity did not seem to affect airway morphogenesis, we did measure changes in cell populations within the developing lung. Immunostaining for surfactant protein $\mathrm{C}$ in alveolar type II cells suggested similar type II cell differentiation (Figure 3A). However, staining for podoplanin $(\mathrm{T} 1 \alpha)$, a marker for alveolar type I cells, was diminished in Twist2-IKK $\beta$ ca lungs compared with controls (Figure 3, B and D). Inflammatory chemokines, including $\mathrm{Ccl} 2$, can stimulate fetal lung angiogenesis. ${ }^{30}$ We therefore examined vascular structures in the developing Twist2-IKKßca lungs. Compared with littermate controls, E17 Twist2-IKK $\beta$ ca lungs had more platelet endothelial cell adhesion molecule-1 staining (Figure 3, C and $\mathrm{E}$ ), consistent with increased numbers of endothelial cells and/or increased angiogenesis.

We next tested whether mesenchymal expression of the IKK $\beta$ ca mutant could cause cell autonomous changes in mesenchymal growth factors. Relative expression levels of FgflO and Fgfl 18 were similar in Twist2-IKK $\beta$ ca lungs and controls (Figure 4A), while Twist2-IKK $\beta$ ca lungs had only slightly higher expression of the transcription factorencoding genes Sox9 and Gata4. Because (sex-determining region Y)-box 9 plays a role in mesoderm development and differentiation, ${ }^{31}$ we used flow cytometry to test whether Twist2-IKK $\beta$ ca lungs had changes in the overall mesenchymal progenitor cell populations (Figure 4, B and C). After excluding $\mathrm{CD} 45^{+}$and E-Cadherin/CD324 ${ }^{+}$cells from E15 and E18 fetal lungs, subpopulations of mesenchymal cells were gated based on the expression of the stem cell markers CD29, stem cells antigen-1, CD104b, and CD44. ${ }^{32}$ Twist2-IKK $\beta \mathrm{ca}$ mutants and control littermates showed similar percentages of mesenchymal cells expressing each marker. Of note, we measured an increase in stem cells antigen-1-positive mesenchymal cells in E18 lungs both in control and mutants. These results suggest that mesenchymal cell differentiation during the later stages of lung development was not altered by mesenchymal IKK $\beta$ ca expression.

$\mathrm{NF}-\kappa \mathrm{B}$ activation induces the expression of soluble inflammatory mediators, including chemokines that recruit 
A

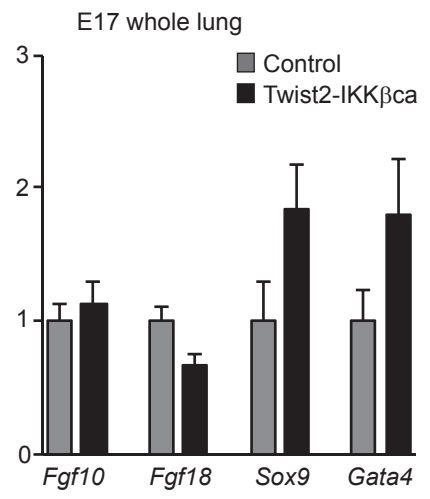

C
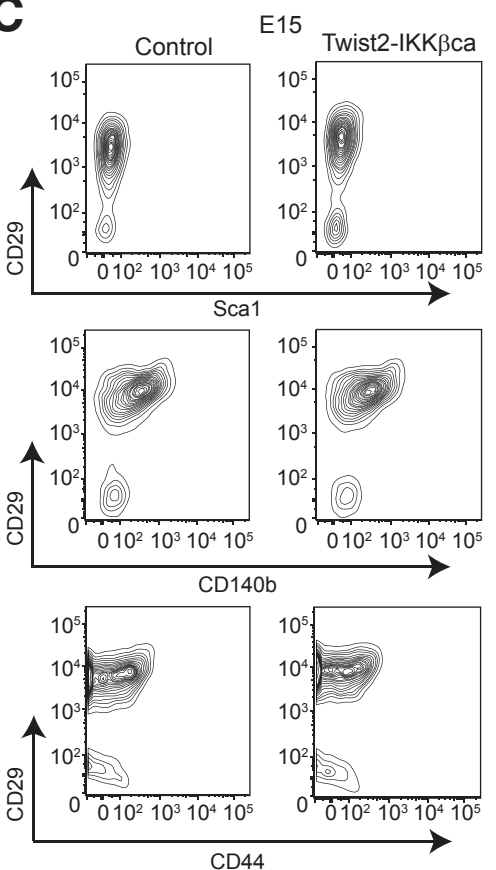

B

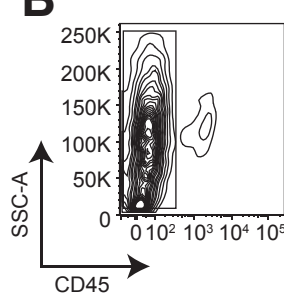

E15
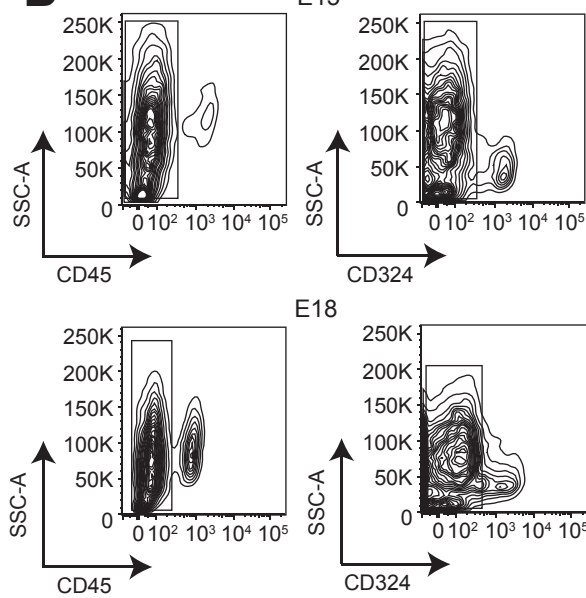

E18
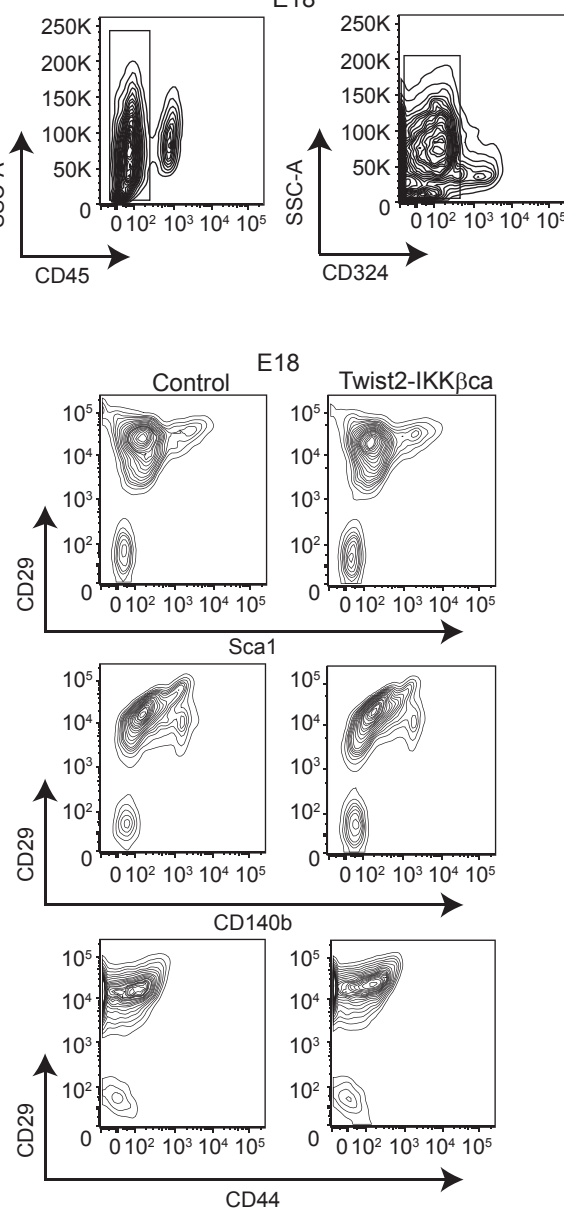

Figure 4 Transgenic inhibitor of NF- $\kappa$ B kinase subunit $\beta$ (IKK- $\beta$ ) activation in fetal lung mesenchyme did not affect mesenchymal developmental gene expression or cause shifts in mesenchymal stem cell populations. A: Measurement of Fgf10, Fgf18, Sox9, and Gata4 mRNA by real-time PCR in E17 embryonic lungs from Twist2constitutively active IKK $\beta$ (IKK $\beta \mathrm{ca}$ ) and control littermates. B: E15 and E18 whole lungs were digested into single cell suspensions. Flow cytometric gating strategy excluded hematopoietic $\left(\mathrm{CD} 5^{+}\right)$and epithelial $\left(\mathrm{CD} 324^{+}\right)$populations. C: Mesenchymal stem cell populations from E15 (left) and E18 (right) Twist2-IKK $\beta c a$ and control embryos were compared by flow cytometry using antibodies against CD29, stem cells antigen (Sca)1, CD140b, and CD44. Data are expressed as means \pm SD (A). Data shown representative of three independent replicates (C). $n=8$ (A). K, 1000.

additional immune cells. Consistent with increased $\mathrm{Ccl} 2$ in Twist2-IKK $\beta$ ca lungs, we detected increased numbers of CD68-expressing macrophages in E17 Twist2-IKK $\beta$ ca lungs compared with controls (Figure 5A). We did not measure differences in the percentages of macrophages staining positive for phospho-histone $\mathrm{H} 3$, suggesting that the increase was not due to cell proliferation. Therefore, the increase in macrophage number was most likely due to the recruitment of additional macrophages to the lung. To test whether these additional macrophages were activated in Twist2-IKK $\beta$ ca lungs, we isolated E18 lung macrophages from control and Twist2-IKK $\beta$ ca embryos and measured the expression of several inflammatory genes induced in activated macrophages. Fetal macrophages isolated from E18 lungs showed no differences in $\mathrm{Illb}, \mathrm{CxcllO}, \mathrm{Ccl} 3$, or the alveolar macrophage marker Mrcl (encoding CD206) between mutants and controls (Figure 5B). Therefore, while $\mathrm{NF}-\kappa \mathrm{B}$ activation in the fetal lung mesenchyme did recruit macrophages to the lung, it did not appear to be sufficient for causing macrophage activation.

Recent data have implicated inflammasome activation and subsequent IL-1 $\beta$ release as key steps linking inflammation and defective lung development. ${ }^{18}$ Inflammasome assembly and activation are required for $\mathrm{IL}-1 \beta$ release, and several genes encoding inflammasome components are induced by inflammatory signals. We therefore tested how mesenchymal IKK $\beta$ activity might affect inflammasome component expression. Compared with controls, E15 Twist2-IKK $\beta$ ca lungs expressed increased mRNA levels of Nlrp3 and Casp11 but similar levels of Nlrc4 and Asc (Figure 6A). However, 

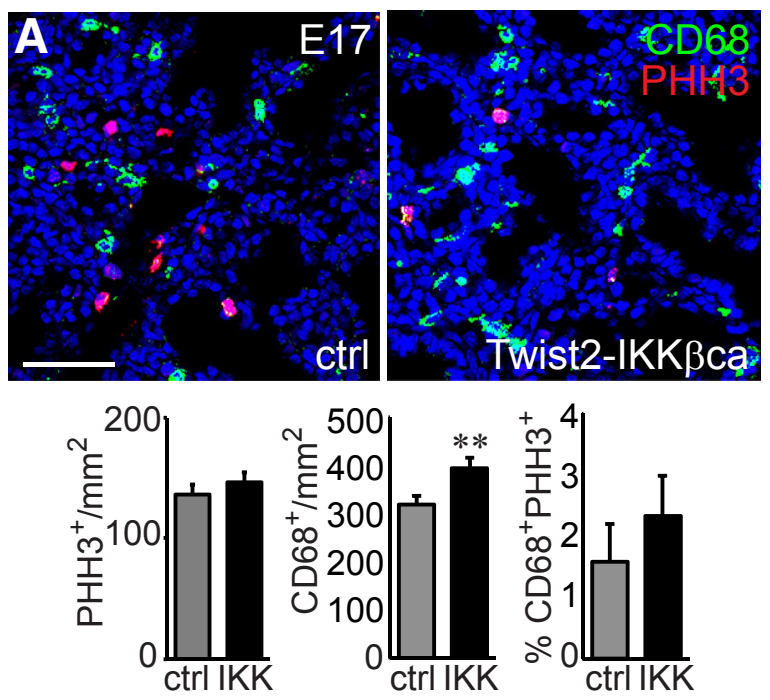

\section{B}

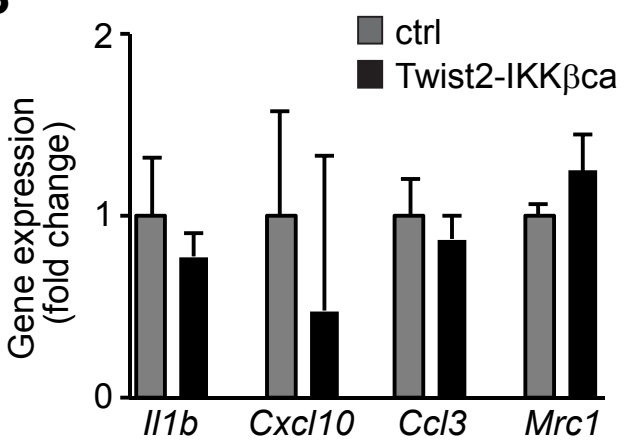

Figure 5 Mesenchyme specific NF- $\kappa B$ activation increases macrophage numbers in fetal lung. A: Identification of proliferation and fetal lung macrophages in E17 lung sections from Twist2-constitutively active IKK $\beta$ (IKK $\beta \mathrm{ca}$ ) and littermate control embryos. Sections were immunostained with antibodies against the macrophage marker CD68 and proliferation marker phospho-histone $\mathrm{H} 3$ ( $\mathrm{PHH} 3)$. Nuclei were labeled with DRAQ5. Twist2-IKK $\beta$ ca lungs contained increased numbers of $\mathrm{CD}^{+} 8^{+}$macrophages, but with no increase in the number of macrophages positive for PHH3. B: Gene expression in isolated E18 fetal lung macrophages. Realtime PCR did not measure significantly different mRNA levels of Il1b, Cxcl10, $C \mathrm{Cl} 3$, or Mrc1 in Twist2-IKK $\beta$ ca macrophages compared with littermate controls. Data are expressed as means \pm SD. $n=3(\mathbf{A}) ; n=3$ to 5 (B). ${ }^{* *} P<0.01$ versus control. Scale bar $=50 \mu \mathrm{m}$.

inflammasome component expression in cultured E15 lung mesenchymal cells was similar in cells from Twist2-IKK $\beta \mathrm{ca}$ embryos and controls (Figure 6B). Twist2-IKK $\beta$ ca mesenchymal cells expressed higher $C c l 2$, consistent with our data from whole-lung samples. To test whether mesenchymal IKK $\beta$ activity could affect where inflammasome proteins were actually expressed in vivo, we used confocal microscopy to identify cells expressing the activated, cleaved form of caspase 1 and NLRP3 (Figure 6C). In E17 lungs, both cleaved caspase 1 and NLRP3 appeared to be restricted to macrophages. Cultured lung mesenchymal cells from Twist2IKK $\beta$ ca embryos also did not release increased amounts of IL-1 $\beta$ protein upon stimulation with LPS and/or ATP, compared with controls (Figure 6D). Therefore, while IKK $\beta$ activity in mesenchymal cells increased the expression of the chemokine-encoding gene $C c l 2$ and some inflammasomeencoding genes throughout the lung, we detected significant inflammasome assembly only in lung macrophages.

\section{Discussion}

Our data demonstrate that increased IKK $\beta$ activity in mesenchymal cells increased $C c l 2$ expression but was not sufficient for affecting lung airway morphogenesis. We were surprised to find normal airway development in Twist2-IKK $\beta$ ca mice given data from our group and others using in vivo models and lung explants that show reduced saccular airway branching with endotoxin exposure or inflammatory activation in lung macrophages. $7,17,33,34$ Inflammation in these other models influenced gene expression in both lung mesenchyme and epithelium. However, bypassing the initial macrophage-mediated response using the mesenchymal Twist2-Cre to drive the expression of IKK $\beta$ ca failed to cause the same degree of defects. Consistent with normal airway branching, embryonic lungs in Twist2-IKK $\beta$ ca mice did not have changes in the expression of $F g f 10$, a gene encoding an important upstream mesenchymal growth factor involved in branching morphogenesis. ${ }^{22,35,36}$

The inflammatory cytokine IL- $1 \beta$ inhibits late-stage lung development. ${ }^{18,37}$ While $I l l b$ mRNA can be induced by inflammatory stimuli, the release of the bioactive peptide requires cleavage of pro-IL- $1 \beta$ by inflammasome complexes containing activated caspases. ${ }^{38}$ Both LPS and the transgenic expression of IKK $\beta \mathrm{ca}$ in macrophages lead to IL-1 $\beta$ release in fetal lungs. ${ }^{17,18}$ However, the Twist2-IKK $\beta \mathrm{ca}$ lungs studied here did not contain increased $I l l b$ mRNA. In addition, Twist2-IKK $\beta$ ca mesenchymal cells did not release IL-1 $\beta$ peptide when stimulated with LPS or the inflammasome activator ATP. Adding both agents may have released a small amount of IL-1 $\beta$ peptide, but the levels were not significantly above those in controls. Embryonic lung mesenchymal cells did not appear to express active inflammasome complexes. Several inflammasome gene components were higher in Twist2-IKK $\beta$ ca cells compared to controls. However, immunostaining for the inflammasome components NLRP3 and caspase 1 showed expression only in lung macrophages. So while the increased expression in Twist2-IKK $\beta$ ca lungs may have been consistent with previous data showing LPS induction of inflammasome genes, ${ }^{18}$ the expression of the IKK $\beta \mathrm{ca}$ transgene was not sufficient for generating the ectopic expression of functional inflammasome complexes in lung mesenchymal cells. We speculate that restricting inflammasome complex expression to professional immune cells such as macrophages both is energetically favorable and helps to limit the spread of inflammation and injury throughout developing tissues.

The chemokine-encoding gene $\mathrm{Ccl} 2$ was elevated in Twist2-IKK $\beta$ ca lungs and mesenchymal cells, suggesting 
A E15 whole lung
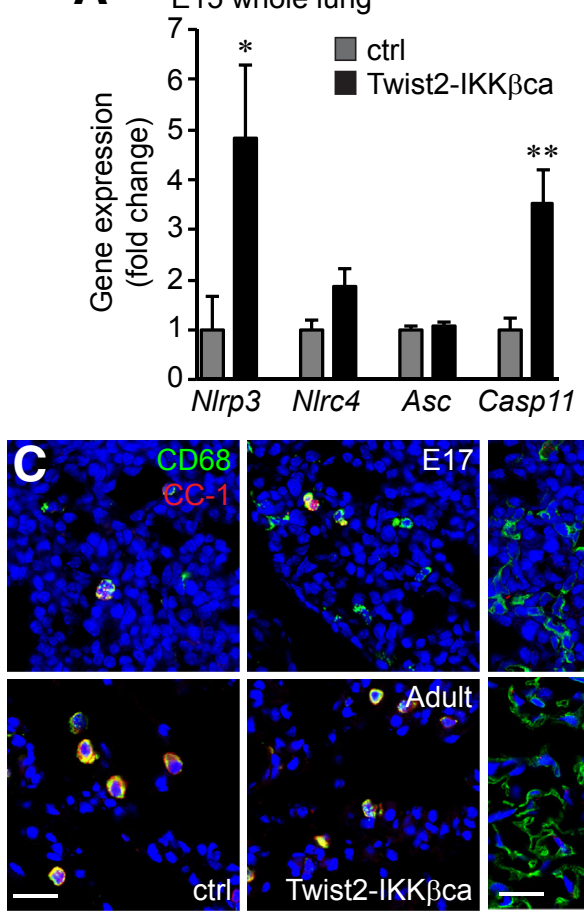

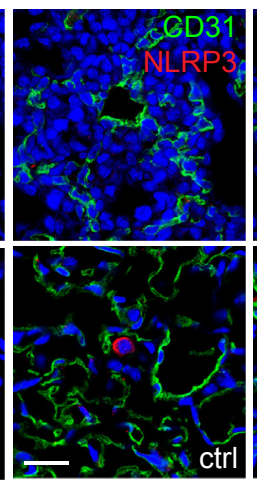

B

B E15 lung mesenchyme
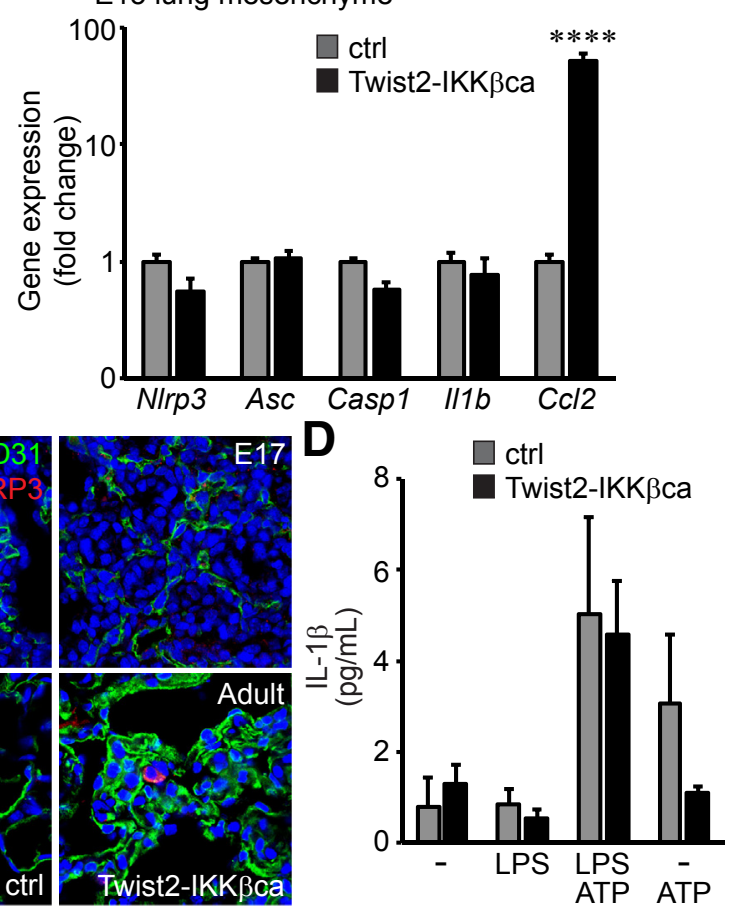

Figure 6 Mesenchyme-specific inhibitor of NF-KB kinase subunit $\beta$ (IKK)- $\beta$ activation does not induce inflammasome expression or IL-1 $\beta$ release. A: Expression levels of the inflammasome components Nlrp3, Nlrc4, Asc, and Casp11 in total lung samples were measured by real-time PCR. Nlrp3 and Casp11 were expressed at higher levels in Twist2-constitutively active IKK $\beta$ (IKK $\beta \mathrm{ca}$ ) lungs compared with littermate controls. B: Expression of inflammasome components in E15 lung mesenchymal cells was similar in Twist2-IKK $\beta c$ ca cells compared with controls. Increased expression of the chemokine $C c l 2$ expression demonstrated NF-KB activation in Twist2-IKKßca cells. C: E17 and adult lung sections were immunostained for colocalization of inflammasome components cleaved caspase (CC)-1, (nucleotide-binding oligomerization domain-containing protein)-like receptor protein (NLRP)-3, macrophages (CD68), and endothelial cells (CD31). Nuclei were labeled with DRAQ5. CC1 and NLRP3 expression is restricted to macrophages in both E17 and adult lungs, both in Twist2-IKK $\beta$ ca and controls. D: Measurement of IL-1 $\beta$ in media of E15 lung mesenchymal cells from Twist2-IKK $\beta$ ca and control embryos treated with lipopolysaccharide (LPS) (250 $\mathrm{ng} / \mathrm{mL}$ ) and/or ATP $(5 \mathrm{mmol} / \mathrm{L})$ as measured by enzyme-linked immunosorbent assay. Cells from Twist2-IKK $\beta$ ca embryos did not release higher levels of IL-1 $\beta$ compared with control cells. Data are expressed as means \pm SD. $n=4$ (A); $n=9$ (B); $n=3$ to 5 (D). ${ }^{*} P<0.05,{ }^{* *} P<0.01$, and ${ }^{* * * * P}<0.0001$ versus control. Scale bars $=25 \mu \mathrm{m} .-$, no treatment.

that IKK $\beta / N F-\kappa B$ activity in fetal lung mesenchymal cells may activate a different set of inflammatory mediators compared with macrophages or other immune cell populations. We recently published data showing the LPS response in fetal mouse lung mesenchymal cells. ${ }^{39}$ While $I l l b, T n f, C c l 3$, and Ccl4 induction has been reported in LPS-treated macrophages, ${ }^{40}$ LPS did not increase their expression in fetal mouse lung mesenchymal cells. LPS did, however, strongly increase the expression of other C-C and $\mathrm{C}-\mathrm{X}-\mathrm{C}$ motif chemokine family members, including $\mathrm{Ccl} 2$, Ccl7, Ccl2O, Cxcll, Cxcl5, and Cxcl10. ${ }^{39}$ These differences suggest that the induction of genes like $I L I B$ require transcription factors present in macrophages or other immune cells but perhaps missing in mesenchymal cell populations. Alternatively, mesenchymal cells may have differences in the chromatin landscape that produce a distinct transcriptional response to NF- $\mathrm{KB}$ activation. ${ }^{41-43}$

Embryonic lungs in Twist2-IKK $\beta$ ca mice had increased staining for the endothelial marker platelet endothelial cell adhesion molecule-1. This increase, even if subtle, could represent accelerated lung angiogenesis. Similar changes were seen after LPS-induced chemokine expression in lung explants and in vivo. ${ }^{30}$ CCL2 can have multiple effects on lung cells, stimulating proliferation and migration of lung fibroblasts and airway smooth muscle cells. ${ }^{44,45}$ In addition, CCL2-mediated increases in lung endothelial permeability appear to contribute to cancer cell metastases. ${ }^{46,47}$ Alterations in lung capillary development and vascular permeability could play a role in bronchopulmonary dysplasia pathogenesis. $^{30,48-50}$ While CCL2 and other chemokines might not directly affect airway branching, the changes in lung vasculature and increased numbers of macrophages could predispose the immature lung to injury after a subsequent exposure. In addition, we observed decreased staining for the alveolar type I cell marker T1 $\alpha$. Type I alveolar epithelial cells likely play important roles in facilitating gas exchange and maintaining a dry alveolar space. ${ }^{51}$ However, the consequences of the changes we observed and the mechanisms leading to these changes are not yet known.

These data emphasize the importance of considering cell specificity when designing therapeutic approaches for targeting the inflammatory response. Immune cells, including 
resident lung macrophages and potentially recruited monocytes and neutrophils, may be the major cell populations that produce inflammatory mediators capable of inhibiting airway branching. ${ }^{17,52}$ Likewise, growth factors important for lung development are expressed in specific cellular compartments. ${ }^{53,54}$ Therefore, a strategy to affect inflammation-mediated arrest in lung development might need to specifically target macrophages, while increasing growth factor expression could require targeting mesenchymal cells, epithelia, or even vascular endothelia. Mechanistic in vivo approaches as presented here will help to characterize cell-specific responses and biological roles in lung injury and disease.

\section{References}

1. Jobe AH: Mechanisms of lung injury and bronchopulmonary dysplasia. Am J Perinatol 2016, 33:1076-1078

2. Watterberg KL, Demers LM, Scott SM, Murphy S: Chorioamnionitis and early lung inflammation in infants in whom bronchopulmonary dysplasia develops. Pediatrics 1996, 97:210-215

3. Bose CL, Laughon MM, Dammann CE: Bronchopulmonary dysplasia and inflammatory biomarkers in the premature neonate. Arch Dis Child Fetal Neonatal Ed 2008, 93:F455-F461

4. Stichel H, Backstrom E, Hafstrom O, Nilsson S, Lappalainen U, Bry K: Inflammatory cytokines in gastric fluid at birth and the development of bronchopulmonary dysplasia. Acta Paediatr 2011, 100:1206-1212

5. Paananen R, Husa AK, Vuolteenaho R, Herva R, Kaukola T, Hallman M: Blood cytokines during the perinatal period in very preterm infants: relationship of inflammatory response and bronchopulmonary dysplasia. J Pediatr 2009, 154:39-43.e3

6. Kunzmann S, Collins JJ, Kuypers E, Kramer BW: Thrown off balance: the effect of antenatal inflammation on the developing lung and immune system. Am J Obstet Gynecol 2013, 208: 429-437

7. Prince LS, Dieperink HI, Okoh VO, Fierro-Perez GA, Lallone RL: Toll-like receptor signaling inhibits structural development of the distal fetal mouse lung. Dev Dyn 2005, 233:553-561

8. Wang J, Bao L, Yu B, Liu Z, Han W, Deng C, Guo C: Interleukin1 beta promotes epithelial-derived alveolar elastogenesis via alphavbeta6 integrin-dependent TGF-beta activation. Cell Physiol Biochem 2015, 36:2198-2216

9. Hillman NH, Polglase GR, Pillow JJ, Saito M, Kallapur SG, Jobe AH: Inflammation and lung maturation from stretch injury in preterm fetal sheep. Am J Physiol Lung Cell Mol Physiol 2011, 300: L232-L241

10. Byrne AJ, Mathie SA, Gregory LG, Lloyd CM: Pulmonary macrophages: key players in the innate defence of the airways. Thorax 2015, 70:1189-1196

11. Werner JL, Steele C: Innate receptors and cellular defense against pulmonary infections. J Immunol 2014, 193:3842-3850

12. Schuliga M: NF-kappaB signaling in chronic inflammatory airway disease. Biomolecules 2015, 5:1266-1283

13. Zhang FX, Kirschning CJ, Mancinelli R, Xu XP, Jin Y, Faure E, Mantovani A, Rothe M, Muzio M, Arditi M: Bacterial lipopolysaccharide activates nuclear factor-kappaB through interleukin-1 signaling mediators in cultured human dermal endothelial cells and mononuclear phagocytes. J Biol Chem 1999, 274:7611-7614

14. Rhee SH, Hwang D: Murine Toll-like receptor 4 confers lipopolysaccharide responsiveness as determined by activation of NF kappa B and expression of the inducible cyclooxygenase. J Biol Chem 2000, 275:34035-34040
15. Bitterman PB, Wewers MD, Rennard SI, Adelberg S, Crystal RG: Modulation of alveolar macrophage-driven fibroblast proliferation by alternative macrophage mediators. J Clin Invest 1986, 77:700-708

16. Jiang D, Liang J, Li Y, Noble PW: The role of Toll-like receptors in non-infectious lung injury. Cell Res 2006, 16:693-701

17. Blackwell TS, Hipps AN, Yamamoto Y, Han W, Barham WJ, Ostrowski MC, Yull FE, Prince LS: NF-kappaB signaling in fetal lung macrophages disrupts airway morphogenesis. J Immunol 2011, 187:2740-2747

18. Stouch AN, McCoy AM, Greer RM, Lakhdari O, Yull FE, Blackwell TS, Hoffman HM, Prince LS: IL-1beta and inflammasome activity link inflammation to abnormal fetal airway development. J Immunol 2016, 196:3411-3420

19. Liao J, Kapadia VS, Brown LS, Cheong N, Longoria C, Mija D, Ramgopal M, Mirpuri J, McCurnin DC, Savani RC: The NLRP3 inflammasome is critically involved in the development of bronchopulmonary dysplasia. Nat Commun 2015, 6:8977

20. Hogmalm A, Bry M, Strandvik B, Bry K: IL-1beta expression in the distal lung epithelium disrupts lung morphogenesis and epithelial cell differentiation in fetal mice. Am J Physiol Lung Cell Mol Physiol 2014, 306:L23-L34

21. Benjamin JT, Gaston DC, Halloran BA, Schnapp LM, Zent R, Prince LS: The role of integrin alpha8betal in fetal lung morphogenesis and injury. Dev Biol 2009, 335:407-417

22. Benjamin JT, Smith RJ, Halloran BA, Day TJ, Kelly DR, Prince LS FGF-10 is decreased in bronchopulmonary dysplasia and suppressed by Toll-like receptor activation. Am J Physiol Lung Cell Mol Physiol 2007, 292:L550-L558

23. Benjamin JT, Carver BJ, Plosa EJ, Yamamoto Y, Miller JD, Liu JH, van der Meer R, Blackwell TS, Prince LS: NF-kappaB activation limits airway branching through inhibition of Sp1-mediated fibroblast growth factor-10 expression. J Immunol 2010, 185:4896-4903

24. Carver BJ, Plosa EJ, Stinnett AM, Blackwell TS, Prince LS: Interactions between NF-kappaB and SP3 connect inflammatory signaling with reduced FGF-10 expression. J Biol Chem 2013, 288:15318-15325

25. White AC, Lavine KJ, Ornitz DM: FGF9 and SHH regulate mesenchymal Vegfa expression and development of the pulmonary capillary network. Development 2007, 134:3743-3752

26. White AC, Xu J, Yin Y, Smith C, Schmid G, Ornitz DM: FGF9 and SHH signaling coordinate lung growth and development through regulation of distinct mesenchymal domains. Development 2006, 133:1507-1517

27. Yu K, Xu J, Liu Z, Sosic D, Shao J, Olson EN, Towler DA, Ornitz DM: Conditional inactivation of FGF receptor 2 reveals an essential role for FGF signaling in the regulation of osteoblast function and bone growth. Development 2003, 130:3063-3074

28. Sasaki Y, Derudder E, Hobeika E, Pelanda R, Reth M, Rajewsky K, Schmidt-Supprian M: Canonical NF-kappaB activity, dispensable for B cell development, replaces BAFF-receptor signals and promotes B cell proliferation upon activation. Immunity 2006, 24:729-739

29. Muzumdar MD, Tasic B, Miyamichi K, Li L, Luo L: A global double-fluorescent Cre reporter mouse. Genesis 2007, 45:593-605

30. Miller JD, Benjamin JT, Kelly DR, Frank DB, Prince LS: Chorioamnionitis stimulates angiogenesis in saccular stage fetal lungs via CC chemokines. Am J Physiol Lung Cell Mol Physiol 2010, 298: L637-L645

31. Turcatel G, Rubin N, Menke DB, Martin G, Shi W, Warburton D: Lung mesenchymal expression of Sox9 plays a critical role in tracheal development. BMC Biol 2013, 11:117

32. Sun S, Guo Z, Xiao X, Liu B, Liu X, Tang PH, Mao N: Isolation of mouse marrow mesenchymal progenitors by a novel and reliable method. Stem Cells 2003, 21:527-535

33. Willet KE, Jobe AH, Ikegami M, Newnham J, Brennan S, Sly PD: Antenatal endotoxin and glucocorticoid effects on lung morphometry in preterm lambs. Pediatr Res 2000, 48:782-788

34. Muratore CS, Luks FI, Zhou Y, Harty M, Reichner J, Tracy TF: Endotoxin alters early fetal lung morphogenesis. J Surg Res 2009, 155:225-230 
35. Bellusci S, Grindley J, Emoto H, Itoh N, Hogan BL: Fibroblast growth factor 10 (FGF10) and branching morphogenesis in the embryonic mouse lung. Development 1997, 124:4867-4878

36. Park WY, Miranda B, Lebeche D, Hashimoto G, Cardoso WV: FGF10 is a chemotactic factor for distal epithelial buds during lung development. Dev Biol 1998, 201:125-134

37. Bry K, Whitsett JA, Lappalainen U: IL-1beta disrupts postnatal lung morphogenesis in the mouse. Am J Respir Cell Mol Biol 2007, 36: $32-42$

38. Franchi L, Munoz-Planillo R, Nunez G: Sensing and reacting to microbes through the inflammasomes. Nat Immunol 2012, 13: 325-332

39. Medal RM, Im AM, Yamamoto Y, Lakhdari O, Blackwell TS, Hoffman HM, Sahoo D, Prince LS: The innate immune response in fetal lung mesenchymal cells targets VEGFR2 expression and activity. Am J Physiol Lung Cell Mol Physiol 2017, 312:L861-L872

40. Sharif O, Bolshakov VN, Raines S, Newham P, Perkins ND: Transcriptional profiling of the LPS induced NF-kappaB response in macrophages. BMC Immunol 2007, 8:1

41. Kaikkonen MU, Spann NJ, Heinz S, Romanoski CE, Allison KA, Stender JD, Chun HB, Tough DF, Prinjha RK, Benner C, Glass CK: Remodeling of the enhancer landscape during macrophage activation is coupled to enhancer transcription. Mol Cell 2013, 51:310-325

42. Bhatt D, Ghosh S: Regulation of the NF-kappaB-mediated transcription of inflammatory genes. Front Immunol 2014, 5:71

43. Ahmed AU, Williams BR, Hannigan GE: Transcriptional activation of inflammatory genes: mechanistic insight into selectivity and diversity. Biomolecules 2015, 5:3087-3111

44. Singh SR, Sutcliffe A, Kaur D, Gupta S, Desai D, Saunders R, Brightling CE: CCL2 release by airway smooth muscle is increased in asthma and promotes fibrocyte migration. Allergy 2014, 69: $1189-1197$

45. Sanchez O, Marcos E, Perros F, Fadel E, Tu L, Humbert M, Dartevelle P, Simonneau G, Adnot S, Eddahibi S: Role of endotheliumderived CC chemokine ligand 2 in idiopathic pulmonary arterial hypertension. Am J Respir Crit Care Med 2007, 176:1041-1047
46. Roblek M, Strutzmann E, Zankl C, Adage T, Heikenwalder M, Atlic A, Weis R, Kungl A, Borsig L: Targeting of CCL2-CCR2-glycosaminoglycan axis using a CCL2 decoy protein attenuates metastasis through inhibition of tumor cell seeding. Neoplasia 2016, 18:49-59

47. Hauselmann I, Roblek M, Protsyuk D, Huck V, Knopfova L, Grassle S, Bauer AT, Schneider SW, Borsig L: Monocyte induction of E-selectin-mediated endothelial activation releases VE-cadherin junctions to promote tumor cell extravasation in the metastasis cascade. Cancer Res 2016, 76:5302-5312

48. De Paepe ME, Chu S, Hall SJ, McDonnell-Clark E, Heger NE, Schorl C, Mao Q, Boekelheide K: Intussusceptive-like angiogenesis in human fetal lung xenografts: link with bronchopulmonary dysplasia-associated microvascular dysangiogenesis? Exp Lung Res 2015, 41:477-488

49. De Paepe ME, Mao Q, Powell J, Rubin SE, DeKoninck P, Appel N, Dixon M, Gundogan F: Growth of pulmonary microvasculature in ventilated preterm infants. Am J Respir Crit Care Med 2006, 173: 204-211

50. Groneck P, Gotze-Speer B, Oppermann M, Eiffert H, Speer CP: Association of pulmonary inflammation and increased microvascular permeability during the development of bronchopulmonary dysplasia: a sequential analysis of inflammatory mediators in respiratory fluids of high-risk preterm neonates. Pediatrics 1994, 93:712-718

51. Dobbs LG, Johnson MD, Vanderbilt J, Allen L, Gonzalez R: The great big alveolar TI cell: evolving concepts and paradigms. Cell Physiol Biochem 2010, 25:55-62

52. Lee DD, Lal CV, Persad EA, Lowe CW, Schwarz AM, Awasthi N, Schwarz RE, Schwarz MA: Endothelial monocyte-activating polypeptide II mediates macrophage migration in the development of hyperoxia-induced lung disease of prematurity. Am J Respir Cell Mol Biol 2016, 55:602-612

53. Shannon JM, Hyatt BA: Epithelial-mesenchymal interactions in the developing lung. Annu Rev Physiol 2004, 66:625-645

54. Hogan BL, Yingling JM: Epithelial/mesenchymal interactions and branching morphogenesis of the lung. Curr Opin Genet Dev 1998, 8: 481-486 